\title{
Effects of bioturbation on the erodibility of cohesive versus non-cohesive sediments along a current-velocity gradient: A case study on cockles
}

\author{
Baoquan Li ${ }^{\mathrm{a}}$, Francesco Cozzoli ${ }^{\mathrm{b}}$, Laura M. Soissons ${ }^{\mathrm{b}}$, Tjeerd J. Bouma ${ }^{\mathrm{b}, \mathrm{c}, \mathrm{d}, *}$, Linlin Chen ${ }^{\mathrm{a}, *}$ \\ a Yantai Institute of Coastal Zone Research, Chinese Academy of Sciences, Yantai 264003, China \\ ${ }^{\mathrm{b}}$ NIOZ Royal Netherlands Institute for Sea Research, Department of Estuarine and Delta Systems (EDS), and Utrecht University, P.O. Box 140, 4400 AC Yerseke, The \\ Netherlands \\ ${ }^{\mathrm{c}}$ University of Applied Sciences, Vlissingen, The Netherlands \\ d Community \& Conservation Ecology, Faculty of Science and Engineering, University of Groningen, The Netherlands
}

\section{A R T I C L E I N F O}

\section{Keywords:}

Cockle

Cerastoderma edule

Bioturbation

Sediment erosion

Erosion threshold

Erosion rates

\begin{abstract}
A B S T R A C T
Soft-bottom bioturbators are ecosystem engineers in the sense that they can have considerable effects on sediment erodibility and resuspension. The common cockle Cerastoderma edule is a bioturbating filter feeder that is widespread along the European Atlantic coastline. Its presence and activity can decrease sediment erosion thresholds in cohesive sediments but little is known about its effect on non-cohesive sediments. Using controlled annular flume experiments, we investigated the relative effects of different cockle densities on sediment resuspension in cohesive vs. non-cohesive sediments by assessing the following: (i) the mud and sand burrowing behavior of cockles, (ii) critical erosion thresholds, (iii) the mass of eroded sediment and (iv) erosion rates. Our results show that cockles were more active in non-cohesive sediment compared with cohesive sediment. Despite their lower activity, the presence of cockles in cohesive sediment increased sediment erodibility by reducing the critical erosion threshold $\left(U_{\text {crit }}\right)$ and increasing both the mass of eroded sediment and erosion rate. In contrast, cockles had no effect on erodibility in non-cohesive sediment, especially on the eroded sediment mass and erosion rate. The mass eroded was not significantly different between cohesive and non-cohesive sediments when cockles were present. Our experiments show that the increased erodibility of cohesive sediment due to the bioturbation by cockles is density dependent: higher cockle density results in stronger effects on erodibility. Moreover, this increase in cohesive sediment erosion due to cockle bioturbation was positively correlated with current velocity. In contrast, the erosion of non-cohesive sediment only depended on the current stress and was unaffected by cockle density. Considering the high abundance of $C$. edule, its widespread distribution and its extensive activities, the results of this study could be widely applicable to intertidal mud flats around the world.
\end{abstract}

\section{Introduction}

The morphology and ecology of intertidal mudflats are determined by the dynamics between sediment stability and erosion (Kristensen et al., 2013). Intertidal mudflats can have strong seasonal dynamics, with periods of accretion and erosion alternating over a season (Yang et al., 2008). Sediment dynamics can also be event driven, with erosion levels on the order of $100 \mathrm{~mm}$ occurring during a single storm (Hu et al., 2015). Such short-term sediment dynamics on intertidal mudflats are important for understanding the long-term dynamics of ecosystems like seagrass meadows (Suykerbuyk et al., 2016) and salt marshes (Bouma et al., 2016). Thus, understanding the processes controlling sediment dynamics of intertidal flats is of key importance. However, sediment dynamics are complex as they involve interactions between physical, geochemical and biological processes influencing sediment erodibility (Grabowski et al., 2011).

Benthic organisms can act as ecosystem engineers in the sense that their presence or activity may alter erosional processes in the surface sediment layer by modifying both the critical erosion threshold and erosion rate of soft-bottom substrates (Paterson, 1989; Willows et al., 1998; Passarelli et al., 2014). They can be divided into two main functional groups: bio-stabilizers and bio-destabilizers (Widdows and Brinsley, 2002). Bio-stabilizers make the sediment surface more resistant to erosion. For instance, diatoms produce extracellular polymeric substances (EPS), a mucus that creates bonds between particles and thus increases erosion thresholds (Meadows et al., 2012; Paterson, 1997). Additionally, aggregates of tube-building macroinvertebrates stabilize the particles against resuspension and erosion, in concert with

\footnotetext{
* Corresponding authors.

E-mail addresses: tjeerd.bouma@nioz.nl (T.J. Bouma), llchen@yic.ac.cn (L. Chen).
} 
the activities of bacteria and microalgae (Krasnow and Taghon, 1997; Borsje et al., 2014). In contrast, bio-destabilizers or bioturbators (e.g. macrobenthic shellfish or lugworms) destabilize the sediment surface and make it sandier, by continuously bioturbating the sediment, hence resuspending fine particles into the water column (Volkenborn et al., 2007; Volkenborn and Reise, 2006).

In general, sediments can be divided into cohesive and non-cohesive sediments, which strongly differ in erodibility because of their differences in physical and chemical properties (Flemming, 2000; Grabowski et al., 2011). Cohesive sediments contain a significant proportion of silt (i.e., $<63 \mu \mathrm{m}$ diameter), which binds the sediment particles together and makes the sediment harder to erode. Apart from altering erodibility, the grain size distribution of the sediment also influences the structure of the invertebrate community living within the sediment (Flemer et al., 2002; Cozzoli et al., 2013). Although macrobenthic organisms typically have a clear preference for a specific sediment grainsize, many species can occur across a broad range of habitats (Ellingsen, 2002; Cozzoli et al., 2013).

Previous studies on the biological effects of macrobenthos have mostly focused on the destabilization and resuspension of cohesive sediments (e.g. Widdows et al., 1998; Andersen, 2001; Dickhudt et al., 2009; Briggs et al., 2015; Van Colen et al., 2013), even though macrobenthic organisms can also be abundant and hence potentially influence sediment erosion in non-cohesive sediments (Van Colen et al., 2013). For instance, the common cockle $C$. edule, while showing a preference for muddy bottoms, can inhabit sediments with a median grain size ranging from $50 \mu \mathrm{m}$ (fully cohesive) to $250 \mu \mathrm{m}$ (fully noncohesive) (Cozzoli et al., 2013). The biogenic effects of bioturbators may be expected to vary with sediment type and population density. How this subsequently translates into erosion characteristics may, moreover, depend on the physical setting, with cohesive sediments being more typical for low-energy areas and non-cohesive sediments being more typical for high-energy environments. Hence, there is a need for an in-depth study addressing the combined effects of bioturbating behavior, bioturbator density and physical setting on the sediment erosion characteristics of both cohesive and non-cohesive sediments.

The aims of the present study are to compare the bioturbation effects of the cockle $C$. edule on the erosion of both cohesive and noncohesive sediments subject to tidal currents. More specifically, we aimed to (i) provide a visual description of the mud and sand burrowing behavior of cockles, (ii) quantify critical sediment erosion thresholds (i.e., current velocity when erosion starts), (iii) quantify the mass of the eroded sediment and (iv) calculate the net erosion rates. The common cockle $C$. edule is an ideal model species as it inhabits both cohesive and non-cohesive sediments along the European Atlantic coastline and is a well-recognized ecosystem engineer. By its burrowing behavior, $C$. edule has been shown to lower sediment erosion thresholds and change the erosional dynamics of cohesive sediments (Montserrat et al., 2009), but little is known about its effects on non-cohesive sediments. Our experimental study was conducted by gradually increasing current velocities in an annular flume and testing their effects on both cohesive and non-cohesive sediments in the absence and presence of two densities of cockles. We hypothesized that the magnitude of the bioturbation effect of the cockle $C$. edule on sediment resuspension will be dependent on both current velocity and sediment cohesiveness.

\section{Materials and methods}

\subsection{Target organism}

The common cockle $C$. edule is a widespread and dominant suspension-feeding bivalve that lives and burrows in the top few centimeters of sediments along the European Atlantic coastline (Tebble, 1966). Malham et al. (2012) reviewed the biology of $C$. edule, including its genetics, immunology, production, development, feeding energetics, growth, predators, and extrinsic environmental drivers. Cockles are defined as bioturbators as they disturb the sediment and increase turbidity levels by their vertical and horizontal activity and by excreting fecal pellets into the water column (Richardson et al., 1993; Widdows et al., 1998). Cockles may occur in very high densities in some areas, up to 5000 individuals $\mathrm{m}^{-2}$; conditions favoring high density are found in the intermediate to high intertidal zone (between 20 and $60 \%$ of emersion time for tidal cycle) with oceanic salinity levels $\left(35 \mathrm{~g} \mathrm{~L}^{-1}\right)$, intermediate levels of mud content (grain size between 100 and $200 \mu \mathrm{m}$ ) and moderate levels of hydrodynamic stress (between 30 and $70 \mathrm{~cm} \mathrm{~s}^{-1}$ of maximal tidal current velocity) (Coosen et al., 1994; Cozzoli et al., 2014). A moderate density of 500 cockles $/ \mathrm{m}^{2}$ has been estimated to occupy about $16 \%$ and disturb about $29 \%$ of the sediment surface in one week (Flach, 1966). Earlier studies have shown that increasing the presence of cockles can increase sediment erodibility (Ciutat et al., 2006, 2007) and significantly lower the sediment erosion threshold (Neumeier et al., 2006), making it an ideal model species to study the effects of bioturbation.

\subsection{Sediment and animal collection}

Sediment samples were collected from two tidal flats located in the tidal basin of the Oosterschelde estuary in the Netherlands: Zandkreek (cohesive, $51^{\circ} 23^{\prime} 15.5^{\prime \prime} \mathrm{N} 3^{\circ} 49^{\prime} 48.6^{\prime \prime} \mathrm{E}$ ) and Oesterdam (non-cohesive, $\left.51^{\circ} 27^{\prime} 51.5^{\prime \prime} \mathrm{N} 4^{\circ} 13^{\prime} 16.3^{\prime \prime} \mathrm{E}\right)$. These locations are characterized by a low to moderate peak in tidal current $\left(c a .35 \mathrm{~cm} \mathrm{~s}^{-1}\right.$ ) and low wave exposure (Cozzoli et al., 2017), with the average tidal amplitude measured as $290.652 \mathrm{~cm}$ in Zandkreek and $333.182 \mathrm{~cm}$ in Oesterdam. C. edule can occur with an average biomass of $c a .15 \mathrm{~g} \mathrm{AFDW} \mathrm{m}^{-2}$ with peaks up to $100 \mathrm{~g} \mathrm{AFDW} \mathrm{m}^{-2}$ at Zandkreek and an average biomass of $30 \mathrm{~g} \mathrm{AFDW} \mathrm{m}^{-2}$ with peaks up to $200 \mathrm{~g} \mathrm{AFDW} \mathrm{m}^{-2}$ at Oesterdam (Cozzoli et al., 2014). Considering its high abundance, widespread distribution and extensive activities, $C$. edule is expected to affect sediment erosion at these locations and, indeed, on tidal flats throughout the Oosterschelde basin.

At each of the two sites, the top $15 \mathrm{~cm}$ of sediment was collected and transported to the laboratory, and fauna were removed by wet-sieving through a $1 \mathrm{~mm}$ mesh. Sieving also removed shell debris and other larger particles or sediment aggregates that may influence sediment erodibility. Particle Size Distribution D50 is the median diameter or the medium value of the particle size distribution and is considered an important parameter characterizing particle size. The mud content (fraction of sediment particles < $63 \mu \mathrm{m}$; Montserrat et al., 2009) and the median grain size data of both sediment types were measured using a Mastersizer 2000 (Malvern Instruments Ltd., Malvern, UK). Non-cohesive sediments (median grain-size D50 $=273.92 \mu \mathrm{m}$ ) were defined as sandy sediments containing $0 \%$ silt (Fig. 1A), and cohesive sediments were defined as muddy sediments with $\geq 32 \%$ silt content (median grain-size D50 = $101.43 \mu \mathrm{m})$ (Fig. 1B).

Specimens of the cockle $C$. edule were collected from the Oesterdam, located in Zeeland, the Netherlands, and transported to the laboratory. After collection, the cockles were left to acclimate in buckets filled with aerated seawater for $24 \mathrm{~h}$ in a temperature-controlled room at $15^{\circ} \mathrm{C}$. After this period, active cockles were transferred to flumes, which had been previously filled with sediment, and left for another $48 \mathrm{~h}$ before starting the experiment. The average shell length of the selected cockles was $36.0 \pm 1.2 \mathrm{~mm}(\mathrm{n}=96)$ with a range from $31.7 \mathrm{~mm}$ to $38.2 \mathrm{~mm}$. The majority of the cockles dug into the sediment and buried themselves in $<10 \mathrm{~min}$ after they were introduced to the sediment surface. When individuals were inactive and remained on the sediment surface for one day, they were replaced with new individuals. Two different densities of cockles were used in the experiments, which were set according to the relevant densities at the sites where sediments were collected (Cozzoli et al., 2014): a low density (LD) of 228 ind. $\mathrm{m}^{-2}$ with a biomass of $14.1 \mathrm{~g}$ ash-free dry weight (AFDW) $\mathrm{m}^{-2}(\mathrm{n}=3)$, and a high density (HD) of 686 ind. $\mathrm{m}^{-2}$ with the biomass of 


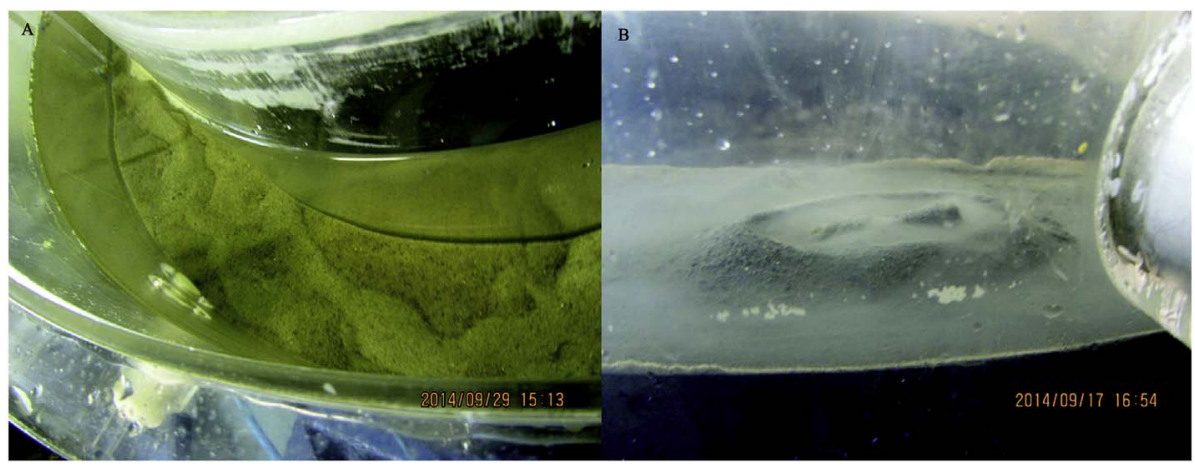

Fig. 1. Visual differences in the mud and sand burrowing behavior of cockles impacted the surface topography in non-cohesive sandy sediment ( $0 \%$ silt) (A) and in cohesive muddy sediment ( $\geq 32 \%$ silt) (B).
42.24 $\mathrm{g} \mathrm{AFDW} \mathrm{m}^{-2}(\mathrm{n}=3)$.

\subsection{Annular flumes and experimental setup}

The annular flumes (surface area of $0.157 \mathrm{~m}^{2}$ ) used for determining the erosion thresholds and erosion rates were developed following the design described by Widdows et al. (1998). For the flume experiments, a consolidated sediment bed was constructed by placing a $7 \mathrm{~cm}$ layer of gravel on the bottom of each flume, followed by a plankton net and, finally, a $10 \mathrm{~cm}$ layer of sieved sediment on top. The $10 \mathrm{~cm}$ layer of sieved sediment was mixed by hand or with a stainless steel sheet to create a smooth and homogeneous mass. The gravel bed under the sediment layer was used for water drainage, which was needed to compact the sieved sediment layer. After a sediment compaction period of 4 days inside the flumes, $31 \mathrm{~L}$ of sea water was gently pumped into the flumes while keeping a 'bubble wrap' layer on top of the sediment to prevent sediment disturbance. The flumes were left for another 3 days before starting the experiment.

To mimic the typical tidal current dynamics found at our collection sites (see Bouma et al., 2005 and Cozzoli et al., 2017 for hydrodynamics at a very similar site), each experimental run consisted of a gradual increase in current velocity from 0.05 to $0.4 \mathrm{~m} \mathrm{~s}^{-1}$ using steps of $0.05 \mathrm{~cm} \mathrm{~s}^{-1}$. Each step lasted $20 \mathrm{~min}$ in the time series analysis. This setup allowed us to measure both the erosion rate and the final equilibrium suspended sediment concentration (SSC) reached at each current velocity step. Current velocity was increased using a flat annular lid driven by a microprocessor-controlled engine. An acoustic Doppler Velocimeter probe (ADV) was used to calibrate water velocity as a function of the rotation speed. Changes in SSC were recorded every $30 \mathrm{~s}$ during each experimental run with an optical backscatter sensor (OBS $3+$, Campbell scientific). The flumes were located in a temperaturecontrolled room set at $15{ }^{\circ} \mathrm{C}$, which is similar to the average temperature found under field conditions. For each flume, an experimental run (without cockles) was conducted to provide an independent control for later runs. An experimental measurement with cockles was conducted $48 \mathrm{~h}$ after the animals had been left for acclimation in the flumes.

The OBS output (expressed as Natural Turbidity Unit) was calibrated against the gravimetric analysis results of water samples taken during the experiment. Water samples of a known volume between 200 and $300 \mathrm{~mL}$ were taken from the flumes at the end of each of the eight current velocity steps. These water samples were filtered through preweighed glass fiber (GFC) filters, which were then oven dried at $70{ }^{\circ} \mathrm{C}$ for $>24 \mathrm{~h}$ and weighed again to obtain the turbidity value.

\subsection{Erosion threshold and erosion rates}

The erosion threshold, expressed as critical current velocity ( $U$, $\mathrm{m} \mathrm{s}^{-1}$ ), was estimated as the intercept from a regression of measured SSC against $U$, following Kristensen et al. (2013). Net erosion rates (E, $\mathrm{mg} \mathrm{m} \mathrm{m}^{-2} \mathrm{~s}^{-1}$ ) were calculated by the following formula (Eq. (1)):

$E=d M / d t=\left(S S C_{\text {end }}-S S C_{\text {start }}\right)^{*} V / A^{*} \Delta t$ where $M$ is the eroded mass, $S S C_{\text {end }}$ is the final suspended sediment concentration as measured during the last time step, $S S C_{\text {start }}$ is the final suspended sediment concentration as measured during the previous time step ( $\left.\mathrm{mg} \mathrm{mL}^{-1}\right), V$ is the volume of the flume $\left(31 \times 10^{3} \mathrm{~mL}\right), A$ is the flume channel basal area $\left(0.157 \mathrm{~m}^{2}\right)$ and $t$ is the duration of the last step in seconds (Quaresma et al., 2004; Kristensen et al., 2013). The mass of sediment eroded (MSE, $\mathrm{mg} \mathrm{m}^{-2}$ ) was calculated by the following formula (Eq. (2)):

$M S E=\frac{S S C^{*} V}{A}$

\subsection{Statistical analysis}

In all experiments, we ran three replicates for each of the two cockle densities and six replicates of the control treatment (i.e., 3 controls each for two cockle densities). These replicates were used to obtain the mean values and standard errors representative of the turbidity under a certain current velocity. To measure the combined effects of current velocity and cockle density on the suspended sediment $\left(\mathrm{mg} \mathrm{mL}^{-1}\right)$ for each current velocity, we averaged all turbidity readings collected during the last $2.5 \mathrm{~min}$ at that current velocity. One-way ANOVA and two-way ANCOVA were used to test the significant differences between experimental groups. For the ANCOVA, sediment type and cockle density were treated as fixed factors and velocity as the covariate. Nonparametric Mann-Whitney rank sum test were used to assess for significant differences when variances were unequal. Statistical tests were performed using the software coPASW Statistics (version 19) with the significance level set at 0.05 . All the variables were normalized by log $(\mathrm{X}+1)$ transformation prior to analysis.

\section{Results}

\subsection{Cockle behavior in non-cohesive vs. cohesive sediment}

There were visual differences in the way cockles impacted the surface topography of the two sediment types. In the non-cohesive sediment, all individuals ploughed the sediment, leaving evident tracks of movement on the surface that were $>10 \mathrm{~cm}$ in length. In contrast, all individuals stayed in place in the cohesive sediment and no tracks were found on the sediment surface. Only valve-abduction behavior was observed in the cohesive sediment, through which the cockles were able to rework the sediment within an area of about $0.5 \mathrm{~cm}$ around themselves over 2-3 days.

3.2. Time series analysis: suspended sediment changes at different current velocities

In the cohesive sediment, the SSC of control treatments (no cockles) gradually increased when the current velocity was higher than $15 \mathrm{~cm} \mathrm{~s}^{-1}$ (Fig. 2A). In contrast, the SSC for cockle treatments (at both 


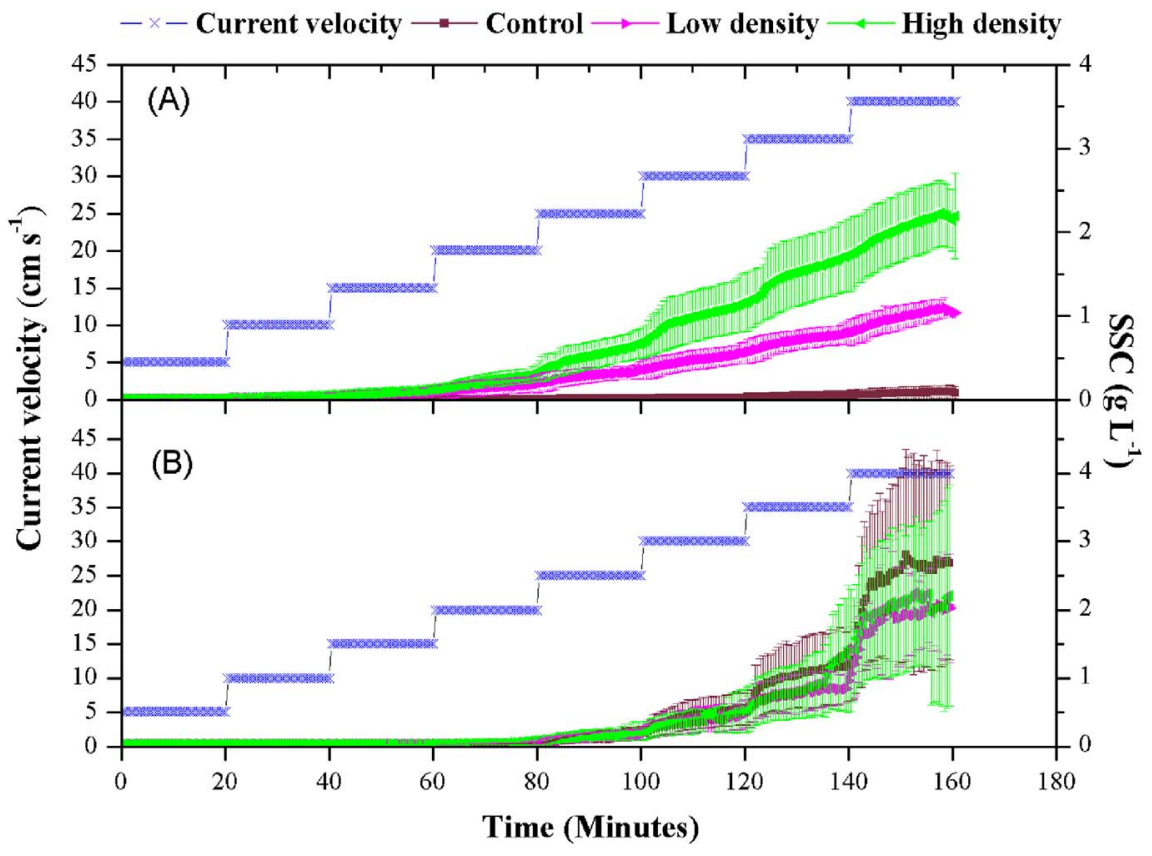

Fig. 2. Time series of suspended sediment concentration (SSC) in response to incremental increases in current velocity from 5 to $40 \mathrm{~cm} \mathrm{~s}^{-1}$ in cohesive (32\% silt) (A) and non-cohesive ( $0 \%$ silt) sediments (B). Six replicates for the control and 3 replicates each for two density treatments. densities) already increased significantly when the current velocity exceeded $10 \mathrm{~cm} \mathrm{~s}^{-1}$ (Fig. 2A). In the non-cohesive sediment, the SSC rapidly increased for all three treatments (control, low and high density of cockles) when the current velocity exceeded $13 \mathrm{~cm} \mathrm{~s}^{-1}$ (Fig. 2B).

We found a significant multiple linear regression between SSC and velocity, cockle density and sediment type $(\mathrm{F}=19.2 \mathrm{p}<0.05$, two way ANCOVA; Table 1). Cockle density showed a positive relationship with SSC, e.g., higher density resulted in higher SSC values ( $F=4.72$ $\mathrm{p}<0.05$, two-way ANCOVA; Table 1, Fig. 2A). Increasing current velocity also significantly increased SSC $(\mathrm{F}=94.05, \mathrm{p}<0.05$, twoway ANCOVA; Table 1, Fig. 2A). The interaction between cockle density and sediment type had a positive influence on sediment erosion $(\mathrm{F}=5.2, \mathrm{p}<0.05$, two-way ANCOVA). However, the SSC of all treatments along the current velocity gradient between the two types of sediments was not significantly different $(\mathrm{F}=1.21 \mathrm{p}>0.05$, two way ANCOVA).

\subsection{Erosion thresholds and net erosion rates}

In cohesive sediment (Fig. 3A), the presence of cockles significantly decreased the critical erosion threshold (i.e., current velocity where erosion starts) from $14.4 \pm 3.8 \mathrm{~cm} \mathrm{~s}^{-1}$ in the control treatment to $10.0 \pm 1.4 \mathrm{~cm} \mathrm{~s}^{-1}$ in the low-density treatment and $10.6 \pm 0.4 \mathrm{~cm} \mathrm{~s}^{-1}$ in the high-density treatment $\quad(\mathrm{F}=6.16$,

Table 1

The statistical analysis results on suspended sediment concentration (SSC) and velocity, cockles density and sediment type (tests of between-subjects effects).

\begin{tabular}{llllll}
\hline \multicolumn{2}{l}{ Dependent variable: SSC } & & & & \\
\hline Source & Type III sum of squares & df & Mean square & F & Sig. \\
\hline Corrected model & $.941^{\mathrm{a}}$ & 6 & 0.157 & 19.188 & 0.000 \\
Intercept & 0.140 & 1 & 0.140 & 17.161 & 0.000 \\
Velocity & 0.768 & 1 & 0.768 & 94.052 & 0.000 \\
Density & 0.077 & 2 & 0.039 & 4.720 & 0.014 \\
Sediment & 0.010 & 1 & 0.010 & 1.214 & 0.277 \\
Density $*$ sediment & 0.085 & 2 & 0.043 & 5.211 & 0.010 \\
Error & 0.335 & 41 & 0.008 & & \\
Total & 2.079 & 48 & & & \\
Corrected total & 1.275 & 47 & & & \\
\hline
\end{tabular}

R squared $=0.737$ (adjusted $\mathrm{R}$ squared $=0.699$ ). $\mathrm{p}<0.05$, ANOVA). The net erosion rates noticeably increased with each incremental increase in current velocity in all three treatments: i.e., control treatment, low-density treatment and high-density treatment (Table 2, Fig. 3A).

In non-cohesive sediment, both the erosion threshold and net erosion rates in all treatments were significantly different from those found in cohesive sediment (Fig. 3B). However, the critical erosion thresholds did not significantly differ among treatments in the non-cohesive sediment, with a mean of $13.1 \pm 0.1 \mathrm{~cm} \mathrm{~s}^{-1}$ in the control treatment, $12.4 \pm 0.2 \mathrm{~cm} \mathrm{~s}^{-1}$ in the low-density cockle treatment and $12.2 \pm 0.8 \mathrm{~cm} \mathrm{~s}^{-1}$ in the high-density cockle treatment (Table 2, Fig. 3B). The net erosion rates significantly increased with current velocity in all three treatments, and the presence of cockles did not significantly affect erosion in the non-cohesive sediment, in contrast to the effect of increasing current velocity (the statistical results are shown in detail in Table 2).

\subsection{Combined effect of current velocity and cockles on cohesive vs. non-} cohesive sediment

In the control treatments, SSCs in the non-cohesive sediment were significantly higher than those found in the cohesive sediment $\left(\chi^{2}=6.4, p<0.05\right.$, Kruskal Wallis Test), especially when the current velocity was higher than $25 \mathrm{~cm} \mathrm{~s}^{-1}$ (Fig. 4A). In the cockle treatments, however, even though SSCs were enhanced in cohesive sediment after introducing both densities of cockles, the SSCs between sediment types were not significantly different due to the integrated effect of current velocity ( $\mathrm{F}=1.1, \mathrm{p}>0.05$, two way ANCOVA) (Fig. 4B and $\mathrm{C}$ ).

\section{Discussion}

The relative effects of bioturbation by cockles on the erodibility of both cohesive and non-cohesive sediments were investigated using controlled annular flume experiments. Our experiments showed that the presence of cockles resulted in a marked increase in sediment erodibility in cohesive sediment, while the erodibility of non-cohesive sediment was mostly unaffected by cockles. The latter result may be explained by the already considerable erosion caused by current stress found in the non-cohesive controls. In the cohesive sediment, the increase in sediment resuspension due to cockle bioturbation was positively correlated with both current velocity and bioturbator density. 


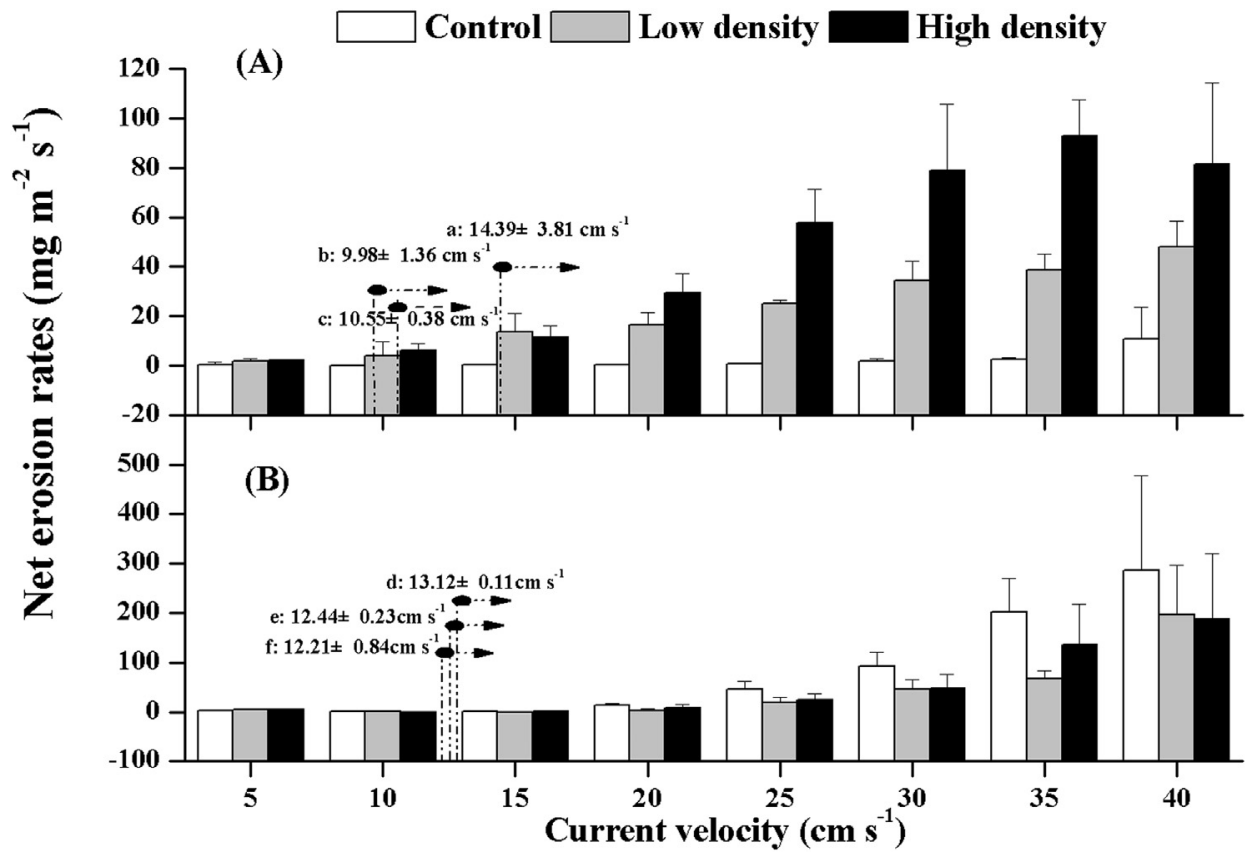

Fig. 3. The net erosion rates for three treatments and 8 current velocities in cohesive (32\% silt) (A) and noncohesive $(0 \%$ silt) sediment (B). The lower case letters, a, b and c, indicate critical erosion threshold values in the control, low-density and high-density cockle treatments in the cohesive sediment, respectively; $\mathrm{d}$, e and $\mathrm{f}$ indicate corresponding values in the non-cohesive sediment, respectively.

Table 2

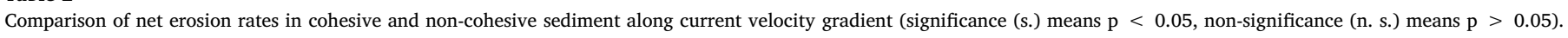

\begin{tabular}{|c|c|c|c|c|c|}
\hline Sediment type & Comparison of net erosion rates & $\mathrm{F}$ or $\mathrm{X}^{2}$ & $\mathrm{p}$ value & Significance & Statistical method \\
\hline \multirow[t]{4}{*}{ Cohesive } & In Control group along the current velocity gradient & 19.7 & $<0.05$ & s. & ANOVA \\
\hline & In Low density group along the current velocity gradient & 60.3 & $<0.05$ & s. & ANOVA \\
\hline & In High density group along the current velocity gradient & 22.3 & $<0.05$ & s. & Kruskal Wallis ANOVA \\
\hline & Between control group (with no cockles) and groups with cockles (at both densities) & 12.1 & $<0.05$ & s. & Kruskal Wallis ANOVA \\
\hline \multirow[t]{4}{*}{ Non-cohesive } & In Control group along the current velocity gradient & 40.7 & $<0.05$ & s. & Kruskal Wallis ANOVA \\
\hline & In Low density group along the current velocity gradient & 21.9 & $<0.05$ & s. & Kruskal Wallis ANOVA \\
\hline & In High density group along the current velocity gradient & 18.6 & $<0.05$ & s. & Kruskal Wallis ANOVA \\
\hline & Between control group (with no cockles) and groups with cockles (at both densities) & 0.16 & $>0.05$ & n. s. & ANOVA \\
\hline
\end{tabular}

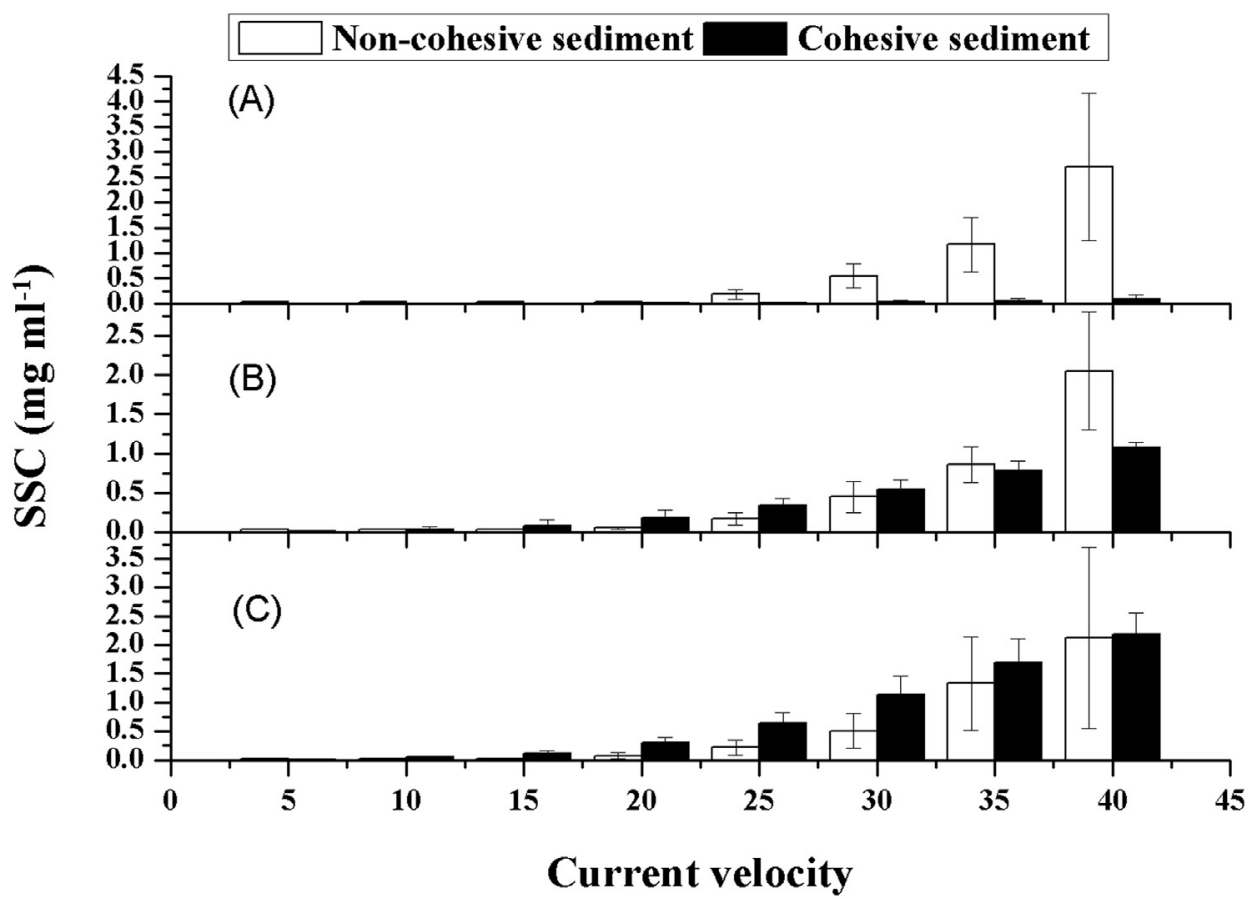

Fig. 4. The suspended sediment concentration (SSC) in cohesive ( $32 \%$ silt) and non-cohesive ( $0 \%$ silt) sediments for control (A), low-density (B) and highdensity cockle treatments $(\mathrm{C})$ 
Interestingly, at current velocities higher than $0.25 \mathrm{~m} \mathrm{~s}^{-1}$, no differences in sediment resuspension were found between the sediment types, with both having the same level of eroded mass. The presence of high densities of bioturbators had the effect of smoothing out the differences in sediment resuspension between cohesive and non-cohesive sediment, leading to the same levels of eroded sediment mass at current velocities higher than $0.25 \mathrm{~m} \mathrm{~s}^{-1}$.

While the cohesive sediment showed more resistance to purely physical stress (increased current velocity) than the non-cohesive sediment, the two types of sediment presented very similar erosion patterns in the presence of cockles. Thus, the presence of cockles, in combination with the effect of current velocity, contributes to increased erodibility in cohesive sediments.

\subsection{Cockle behavior in the cohesive vs. non-cohesive sediment}

Even though the levels of compaction used in the sediments are found within the cockle habitat range, we observed very different behavior of cockles in the cohesive versus non-cohesive sediments during the acclimation period. They roamed across the flumes in the non-cohesive sediment, while remaining quiescent in the cohesive sediment. Previous studies have demonstrated that the cockle $C$. edule can remain active and continue to move periodically or regularly 'shake' after burrowing into sediment, disturbing the upper sediment layers (Flach, 1966). The different movement behavior of the cockles between the types of sediment can be explained by the different properties of the two sediment types. Cohesive sediment has a unique characteristic of cohesion and adhesion induced by inter-particle attraction (Grabowski et al., 2011), which makes it much stronger than non-cohesive sediment. This adhesion of cohesive sediment is likely to obstruct the movement of cockles by requiring much more energy to move. The burrowing and tracking activities of Hydrobia ulvae disrupted the upper layers of sediment, generating a fluff layer, and enhanced the rates of sediment erosion (Andersen et al., 2002; Orvain et al., 2003), which also happened during the similar bioturbation effect of cockles.

\subsection{Cockle bioturbation effects on the erodibility of cohesive and non- cohesive sediment}

This experiment demonstrated the differences in the bioturbation effects of cockles on cohesive and non-cohesive sediments. The presence of cockles can increase erosion rates and decrease erosion thresholds in cohesive sediment, while having no effect in non-cohesive sediment. Sediment erosion is divided into two separate phases, namely, i) erosion of the fluff layer and ii) subsequent bed erosion. Both erosion phases were found to be influenced by the suspension-feeder Scrobicularia plana and mud snail Hydrobia ulvae (Orvain et al., 2003; Orvain, 2005). Based on the bioturbation of H. ulvae on sediment erosion, a 1-dimensional vertical model was developed by Orvain et al. (2003) to predict the community effects. In agreement with this work, our study showed that the presence of $C$. edule can also impact both erosion phases. The functional group approach has also been introduced in studies of sediment erodibility by assessing the interactions between the sediment and the organism (Pearson, 2001). François et al. (2002) also developed a gallery-diffusor model to characterize the bioturbation processes of the polychaete Nereis diversicolor.

In addition to having direct effects on sediment erosion by disrupting the upper layers of sediment (i.e., both enhancing the bed roughness and reducing the sediment strength), C. edule can also have indirect effects. For example, they enhance biodeposition by producing faeces and pseudo-faeces, which may contribute a significant portion of the total accumulation of fine-grained material, namely forming a fluff layer. When subsequently mixed into the sediment, this may increase the mud content, thereby making the sediment more cohesive over time. However, this process will take time, as it has been demonstrated that only a small fraction of these deposits is permanently deposited, whereas the majority is easily resuspended, thereby resulting in more resuspension in the presence of cockles (Andersen et al., 2010). These disturbances can be characterized as being in the same integrated process of fluff layer creation and erosion (Orvain, 2005).

An increase in SSC due to the presence of cockles might lead to a chain reaction or the Butterfly effect (Ciutat et al., 2007), where an increase in SSC will stimulate the frequency of valve opening and closing in cockles, which in turn aggravates the destabilization and resuspension of sediment by resuspending more pseudo-faeces (Navarro and Widdows, 1997; Ciutat et al., 2007). In contrast, another study showed that high cockle density may also dampen or reduce sediment resuspension by producing more mucus to bind sediment particles, thereby enhancing sediment cohesion (Ciutat et al., 2006). In these experiments, we did not find this binding effect. This might be because our high-density treatment level (i.e., 686 ind. $\mathrm{m}^{-2}$ ) is much lower than the high densities found in natural cockle beds, which may be up to thousands of individuals per square meter.

The increase in sediment resuspension was dependent on the interaction between both bioturbator density and current velocity. At low water current velocities under the critical erosion threshold, sediment reworking by animals has negligible impact on erosion. At higher current velocities, however, suspended particles may be transported away by currents and thereby gradually change the sediment properties over time (Wendelboe et al., 2013). Moreover, the intensity of flow speed might initiate and enhance burrowing processes by cockles (St-Onge et al., 2007), which in turn may enhance sediment erodibility through the combined impact from burrowing clams and increased current speed.

As faeces and pseudo-faeces are generally resuspended, and erosion thresholds are reduced, cockles may contribute to making the sediment much sandier over time. Such effects were shown at the large-scale in an in situ lugworm exclusion experiment. Volkenborn et al. (2007) found that Arenicola marina activities could shift a muddy sedimentary system towards sand flats. Demonstrating the long-term effect of cockle bioturbation, however, would require in situ investigations conducted at similarly large spatial and temporal scales.

\section{Conclusions}

The particle composition of a certain type of sediment results from the net import and export of differently sized particles. Bioturbation represents only one of the processes mediating this equilibrium (Wendelboe et al., 2013). The contribution of hydrodynamics and fauna to sediment erosion may be different depending on the type of environment: low $v s$. high energy, low $v$ s. high SSC, or cohesive $v s$. noncohesive sediment. In a low energy environment, macro-organisms like cockles might play a considerable role in mediating sediment composition in cohesive sediments but not in non-cohesive sediments. These non-cohesive sediments, however, are mainly expected in high-energy environments or in low energy areas where no silt is available.

This consideration is further strengthened by the fact that the muddy bottoms characterized by low hydrodynamic energy (i.e., where cockles are more effective in sediment resuspension) are where cockles are more commonly present and where they are able to realize their higher densities (Cozzoli et al., 2013; Cozzoli et al., 2014).

Our results emphasize the conditional outcomes in the bioturbating effects of (high-density) cockles, thereby providing a basis for numerical modelling at the landscape scale (Willows et al., 1998; Lumborg et al., 2006).

\section{Acknowledgments}

This work was conducted as part of the NSFC-NWO "Water ways, Harbours, Estuaries and Coastal Engineering" scheme and was co-supported by the National Natural Science Foundation of China (No. NSFC41061130543) and the Netherlands Organisation for Scientific 
Research (No. 843.10.003), the Key Research Program of the Chinese Academy of Sciences, Grant No. KZZD-EW-14, the Strategic Priority Research Program of the Chinese Academy of Sciences, Grant Nos. XDA11020403 \& XDA1102702, and the Centre of Expertise project Oesterdam.

\section{References}

Andersen, T.J., 2001. Seasonal variation in erodibility of two temperate, microtidal mudflats. Estuar. Coast. Shelf Sci. 53, 1-12.

Andersen, T.J., Jensen, K.T., Lund-Hansen, L., Mouritsen, K.N., Pejrup, M., 2002. Enhanced erodibility of fine-grained marine sediments by Hydrobia ulvae. J. Sea Res. 48, 51-58.

Andersen, T.J., Lanuru, M., van Bernem, C., Pejrup, M., Riethmueller, R., 2010. Erodibility of a mixed mudflat dominated by microphytobenthos and Cerastoderma edule, East Frisian Wadden Sea, Germany. Estuar. Coast. Shelf Sci. 87, 197-206.

Borsje, B.W., Bouma, T.J., Rabaut, M., Herman, P.M.J., Hulscher, S.J.M.H., 2014. Formation and erosion of biogeomorphological structures: a model study on the tubebuilding polychaete Laniceconchilega. Limnol. Oceanogr. 59, 1297-1309.

Bouma, T.J., De Vries, M.B., Low, E., Kusters, L., Herman, P.M.J., Tánczos, I.C., Hesselink, A., Temmerman, S., Meire, P., van Regenmortel, S., 2005. Flow hydrodynamics on a mudflat and in salt marsh vegetation: identifying general relationships for habitat characterisations. Hydrobiologia 540, 259-274.

Bouma, T.J., van Belzen, J., Balke, T., van Dalen, J., KLaassen, P., Hartog, A.M., Callaghan, D.P., Hu, Z., Stive, M.J.F., Temmerman, S., Herman, P.M.J., 2016. Shortterm mudflat dynamics drive long-term cyclic salt marsh dynamics. Limnol. Oceanogr. 61, 2261-2275.

Briggs, K.B., Cartwright, G., Friedrichs, C.T., Shivarudruppa, S., 2015. Biogenic effects on cohesive sediment erodibility resulting from recurring seasonal hypoxia on the Louisiana shelf. Coast. Shelf Sci. 93, 17-26.

Ciutat, A., Widdows, J., Readman, J.W., 2006. Influence of cockle Cerastoderma edule bioturbation and tidal-current cycles on resuspension of sediment and polycyclic aromatic hydrocarbons. Mar. Ecol. Prog. Ser. 328, 51-64.

Ciutat, A., Widdows, J., Pope, N.D., 2007. Effect of Cerastoderma edule density on nearbed hydrodynamics and stability of cohesive muddy sediments. J. Exp. Mar. Biol. Ecol. 346, 114-126.

Coosen, J., Twisk, F., Van Der Tol, M.W.M., Lambeck, R.H.D., Van Stralen, M.R., Meire, P.M., 1994. Variability in stock assessment of cockles (Cerastoderma edule L.) in the Oosterschelde (in 1980-1990), in relation to environmental factors. Hydrobiologia 282, 381-395.

Cozzoli, F., Bouma, T.J., Ysebaert, T., Herman, P.M.J., 2013. Application of non-linear quantile regression to macrozoobenthic species distribution modelling: comparing two contrasting basins. Mar. Ecol. Prog. Ser. 475, 119-133.

Cozzoli, F., Eelkema, M., Bouma, T.J., Ysebaert, T., Escaravage, V., Herman, P.M.J., 2014. A mixed modeling approach to predict the effect of environmental modification on species distributions. PLoS One 9, e89131.

Cozzoli, F., Smolders, S., Eelkema, M., Ysebaert, T., Escaravage, V., Temmerman, S., Meire, P., Herman, P.M.J., Bouma, T.J., 2017. A modeling approach to assess coastal management effects on benthic habitat quality: a case study on coastal defense and navigability. Estuar. Coast. Shelf Sci. 184, 67-82.

Dickhudt, P.J., Friedrichs, C.T., Schaffner, L.C., Sanford, L.P., 2009. Spatial and temporal variation in cohesive sediment erodibility in the York River estuary, eastern USA: a biologically influenced equilibrium modified by seasonal deposition. Mar. Geol. 267 (3-4), 128-140.

Ellingsen, K.E., 2002. Soft-sediment benthic biodiversity on the continental shelf in relation to environmental variability. Mar. Ecol. Prog. Ser. 232, 15-27.

Flach, E.C., 1966. The influence of the cockle, Cerastoderma edule on the macrozoobenthic community of tidal flats in the Wadden Sea. Mar. Ecol. 17, 87-98.

Flemer, D.A., Ruth, B.F., Bundrick, C.M., 2002. Effects of sediment type on microbenthic infaunal colonization of laboratory microcosms. Hydrobiologia 485, 83-96.

Flemming, B.W., 2000. A revised textural classification of gravel-free muddy sediments on the basis of ternary diagrams. Cont. Shelf Res. 20, 1125-1137.

François, F., Gérino, M., Stora, G., Durbec, J.P., Poggiale, J.C., 2002. Functional approach to sediment reworking by gallery forming macrobenthic organisms: modeling and application with the polychaete Nereis diversicolor. Mar. Ecol. Prog. Ser. 229, 127-136.

Grabowski, R.C., Droppo, I.G., Wharton, G., 2011. Erodibility of cohesive sediment: the importance of sediment properties. Earth Sci. Rev. 105, 101-120.

Hu, Z., Lenting, W., van der Wal, D., Bouma, T.J., 2015. Continuous monitoring bed-level dynamics on an intertidal flat: introducing novel, stand-alone high-resolution SEDsensors. Geomorphology 245, 223-230.
Krasnow, L.D., Taghon, G.L., 1997. Rate of tube building and sediment particle size selection during tube construction by the tanaid crustacean, Leptochelia dubia. Estuaries $20,534-546$.

Kristensen, E., Neto, J.M., Lundkvist, M., Frederiksen, L., Pardal, M.A., Valdemarsen, T. Flindt, M.R., 2013. Influence of benthic macroinvertebrates on the erodability of estuarine cohesive sediment: density- and biomass-specific response. Estuar. Coast. Shelf Sci. 134, 80-87.

Lumborg, U., Andersen, T.J., Pejrup, M., 2006. The effect of Hydrobia ulvae and microhpytobenthos on cohesive sediment on an intertidal mudflat described by means of numerical modelling. Estuar. Coast. Shelf Sci. 68, 208-220.

Malham, S.K., Hutchinson, T.H., Longshaw, M., 2012. A review of the biology of European cockles (Cerastoderma spp.). J. Mar. Biol. Assoc. U. K. 92, 1563-1577.

Meadows, P.S., Meadows, A., Murray, J.M.H., 2012. Biological modifiers of marine benthic seascapes: their role as ecosystem engineers. Geomorphology 157, 31-48.

Montserrat, F., Colen, C.V., Provoost, P., Milla, M., Ponti, M., Meersche, K.V., Ysebaert, T., Herman, P.M.J., 2009. Sediment segregation by biodiffusing bivalves. Estuar. Coast. Shelf Sci. 83, 379-391.

Navarro, J.M., Widdows, J., 1997. Feeding physiology of Cerastoderma edule in response to a wide range of seston concentrations. Mar. Ecol. Prog. Ser. 152, 17-186.

Neumeier, U., Lucas, C.H., Collins, M., 2006. Erodibility and erosion patterns of mudflat sediments investigated using an annular flume. Aquat. Ecol. 40, 543-554.

Orvain, F., 2005. A model of sediment transport under the influence of surface bioturbation: generalisation to the facultative suspension-feeder Scrobicularia plana. Mar. Ecol. Prog. Ser. 286, 43-56.

Orvain, F., Le Hir, P., Sauriau, P.G., 2003. A model of fluff layer erosion and subsequent bed erosion in the presence of the bioturbator, Hydrobia ulvae. J. Mar. Res. 61, 823-851.

Passarelli, C., Olivier, F., Paterson, D.M., Meziane, T., Hubas, C., 2014. Organisms as cooperative ecosystem engineers in intertidal flats. J. Sea Res. 92, 92-101.

Paterson, D.M., 1989. Short-term changes in the erodibility of intertidal cohesive sediments related to the migratory behaviour of epipelic diatoms. Limnol. Oceanogr. 34, 223-234.

Paterson, D.M., 1997. Biological mediation of sediment erodibility: ecology and physical dynamics. In: Burt, N., Parker, R., Watts, J. (Eds.), Cohesive Sediments. John Wiley \& Sons, London, pp. 215-229.

Pearson, T.H., 2001. Functional group ecology in soft-sediment marine benthos: the role of bioturbation. Oceanogr. Mar. Biol. 39, 233-267.

Quaresma, V., Amos, C., Flindt, M., 2004. The influence of biological activity and consolidation time on laboratory cohesive beds. J. Sediment. Res. 74, 184-190.

Richardson, C.A., Ibarrola, I., Ingham, R.J., 1993. Emergence pattern and spatial distribution of the common cockle Cerastoderma edule. Mar. Ecol. Prog. Ser. 99, 71-81.

St-Onge, P., Miron, G., Moreau, G., 2007. Burrowing behavior of the softshell clam (Mya arenaria) following erosion and transport. J. Exp. Mar. Biol. Ecol. 340, 103-111.

Suykerbuyk, W., Bouma, T.J., Govers, L.L., Giesen, K., de Jong, D.J., Herman, P.M.J., Hendriks, J., van Katwijk, M.M., 2016. Surviving in changing seascapes: sediment dynamics as bottleneck for long-term seagrass presence. Ecosystems 19, 296-310.

Tebble, P., 1966. British Bivale Seashells. Brithish Museum (Natural History), London.

Van Colen, C., Thrush, S.F., Vincx, M., Ysebaert, T., 2013. Conditional responses of benthic communities to interference from an intertidal bivalve. PLoS One 8, e65861.

Volkenborn, N., Reise, K., 2006. Lugworm exclusion experiment: responses by deposit feeding worms to biogenic habitat transformations. J. Exp. Mar. Biol. Ecol. 330, $169-179$.

Volkenborn, N., Hedtkamp, S.I.C., van Beusekom, J.E.E., Reise, K., 2007. Effect of bioturbation and bioirrigation by lugworms (Arenicola marina) on physical and chemical sediment properties and implications for intertidal habitat succession. Estuar. Coast. Shelf Sci. 74, 331-343.

Wendelboe, K., Egelund, J.T., Flindt, M.R., Valdemarsen, T., 2013. Impact of lugworms (Arenicola marina) on mobilization ad transport of fine particles and organic matter in marine sediments. J. Sea Res. 76, 31-38.

Widdows, J., Brinsley, M.D., 2002. Impact of biotic and abiotic processes on sediment dynamic and the consequences to the structure and functioning of the intertidal zone. J. Sea Res. 48, 143-156.

Widdows, J., Brinsley, M.D., Elliot, M., 1998. Use of in situ flume to quantify particle flux (biodeposition rates and sediment erosion) for an intertidal mudflat in relation to changes in current velocity and benthic macrofauna. Geol. Soc. Lond. Spec. Publ. 139, 85-97.

Willows, R.I., Widdows, J., Wood, R.G., 1998. Influence of and infaunal bivalve on the erosion of an intertidal cohesive sediment: a flume and modeling study. Limnol. Oceanogr. 1332-1343.

Yang, S.L., Li, H., Ysebaert, T., Bouma, T.J., Zhang, W.X., Wang, Y.X., Li, P., Li, M., Ding, P.X., 2008. Spatial and temporal variations in sediment grain size in tidal wetlands, Yangtze delta: on the role of physical and biotic controls. Estuar. Coast. Shelf Sci. 77, 657-671. 